\title{
Giant solitary extradural plasmacytoma of the skull: illustrative case
}

\author{
Luis A. Castillejo, MD, José de Jesús Julian, MD, Pedro González, MD, and Rafael Román, MD \\ Department of Neurosurgery, Instituto Mexicano del Seguro Social, Mexico City, Mexico
}

\begin{abstract}
BACKGROUND Solitary extradural plasmacytoma of the skull (SEPS) is an extremely rare entity with only 35 cases reported in the English-language literature. SEPS is a rare presentation of plasma cell dyscrasias, accounting for $4 \%$ of plasma cell tumors. The diagnosis of solitary plasmacytoma requires exclusion of multiple myeloma (MM) and prompt diagnosis and treatment.

OBSERVATIONS The authors describe the case of a 52-year-old man with SEPS. He presented with a painless, progressive, soft swelling mass in the left parietal region. Magnetic resonance imaging revealed a left frontotemporal extra-axial lesion that involved the ipsilateral orbital apex and posterior ethmoidal cells. Biological studies did not reveal features suggestive of MM. A diagnosis of SEPS was based on microscopic examination and immunohistochemical analysis after surgery. The patient had an excellent recovery and was discharged the day after surgery without neurological deficit.
\end{abstract}

LESSONS SEPS is a potentially curable disease, and total resection with or without radiotherapy is associated with a good prognosis and long-term recurrence-free survival. Distinction between SEPS and MM is of paramount importance because the prognosis and treatment differ.

https://thejns.org/doi/abs/10.3171/CASE21127

KEYWORDS extradural; plasmacytoma; solitary; giant; skull

Plasmacytoma is a myelomatous mass that may be solitary, may be seen in combination with multiple myeloma (MM), or may progress to a generalized disease. ${ }^{1}$ The diagnosis of solitary plasmacytoma requires exclusion of MM based on bone marrow aspiration, electrophoresis of serum and urine protein, and no other lesion on the complete skeletal survey. ${ }^{2}$ Solitary extradural plasmacytoma of the skull (SEPS) is a rare finding with 35 cases reported in the English-language literature. It may involve the cranial vault, skull base, and orbit. Distinction between SEPS and MM is of paramount importance because SEPS of the skull vault has a good prognosis after total resection and/or radiotherapy. ${ }^{3}$ We describe a case of SEPS with orbital involvement and brain compression with no light chain restriction on immunohistochemistry and an excellent response to surgical treatment and postoperative radiotherapy.

\section{Illustrative Case}

\section{Description}

A 52-year-old man was admitted to our hospital for a progressive, soft swelling mass in the left frontoparietal region associated with cosmetic skull deformity, headache, and proptosis along with decreased vision in his left eye. His medical history was significant for type 2 diabetes mellitus treated with metformin and glibenclamide. His neurological examination revealed total left eye blindness without any other neurological deficit. His laboratory findings only reported lack of glycemic control with serum glucose of $202 \mathrm{mg} / \mathrm{dL}$. The results of the rest of his serum analysis were normal.

\section{Imaging Findings}

Cranial magnetic resonance imaging revealed a giant left frontotemporal extra-axial lesion with involvement of the ipsilateral orbital apex, posterior ethmoidal cells, and frontal sinus. The lesion was associated with cerebral compression, left subfalcine hernia with ventricular collapse, and left ocular proptosis. The lesion was isointense on T1- and T2-weighted sequences and showed heterogeneous contrast enhancement. Its dural borders were also characterized by contrast enhancement. Magnetic resonance angiography demonstrated prominent tumor supply by distal branches of the external carotid artery. Therefore, preoperative tumor embolization was performed (Fig. 1).

ABBREVIATIONS $\beta 2 \mathrm{M}=\beta_{2}$-microglobulin; $\mathrm{MM}=$ multiple myeloma; $\mathrm{PCLI}=$ plasma cell labeling index; $\mathrm{SEPS}$ = solitary extradural plasmacytoma of the skull. INCLUDE WHEN CITING Published May 24, 2021; DOI: 10.3171/CASE21127.

SUBMITTED February 24, 2021. ACCEPTED March 7, 2021.

(C) 2021 The authors, CC BY-NC-ND 4.0 (http://creativecommons.org/licenses/by-nc-nd/4.0/). 

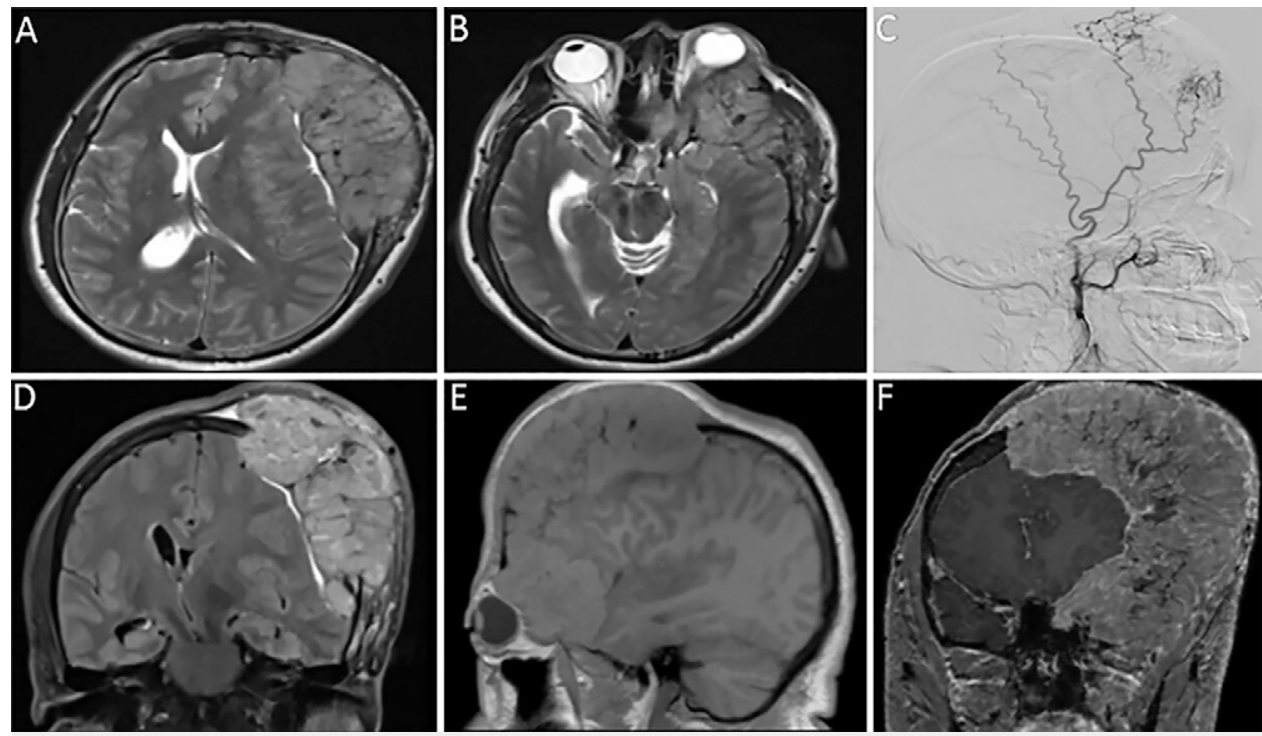

FIG. 1. A: Cranial magnetic resonance imaging (MRI) in an axial T2-weighted section demonstrating the extradural isointense lesion, which causes midline shift and brain compression. B: Tumor involves the optic nerve and the orbital apex. C: Preoperative angiography shows the tumor's extensive vascular supply originating from branches of the superficial temporal artery. D: Cranial MRI in a coronal section shows extension of the tumor to soft tissues and scalp. E: Cranial MRI in a sagittal section allows evaluation of tumor extension to the orbital and cranial vault. F: Cranial MRI in a coronal T1-weighted section reveals the significant size of the tumor and its contrast enhancement.

\section{Operation and Histological Analysis}

The patient underwent surgery via a bifrontal incision and craniotomy (Fig. 2A and B). Surgical findings consisted of a reddish, soft, calcified, and highly vascular lesion that had totally eroded the calvarial bone and extended to the subcutaneous plane (Fig. 2C). The tumor was separated easily from the dura mater, and the marginal bone around the tumor was drilled to ensure complete removal of the tumor (Fig. 2D). Cranioplasty and orbital tumor resection were deferred because of excessive blood loss $(3.5 \mathrm{~L})$ during tumor resection. Pathological analysis was performed, and macroscopic examination revealed a giant hard and brownish tumor with violaceous plaques and abundant osseous tissue (Fig. 3A and B). Histological findings showed abundant plasmatic cells with strong and diffuse expression of CD138, CD56, and CD79, whereas kappa and lambda light chains were negative (Fig. $3 \mathrm{C}-\mathrm{E}$ ). The findings of serum and urine electrophoresis were normal, and the result of a bone marrow biopsy was negative for MM.

\section{Postoperative Course}

Because of hypovolemic shock, the patient was admitted to the intensive care unit with ventilator weaning and resolution of shock within 24 hours. The patient had a full recovery afterward and was discharged after 1 day of floor care. Six-month follow-up studies showed a great response to surgical treatment and radiotherapy (Fig. 4).

\section{Discussion}

\section{Observations}

Plasmacytoma of the skull is a rare finding. It may involve the cranial vault, the skull base, and the orbit. ${ }^{4}$ Cosmetic skull deformities have been reported to be a usual cause for referral to a specialist. ${ }^{4,5}$
Plasmacytoma often lacks neurological symptoms, except in cases of intraparenchymal dissemination or compression of the brain and cranial nerves. $^{4,6}$

The diagnosis of SEPS is based on a radiologically solitary bone lesion, plasma cells in the biopsy specimen, less than $5 \%$ plasma cells in bone marrow, less than $2 \mathrm{~g} / \mathrm{dL}$ monoclonal protein ( $\mathrm{M}$ protein) in the serum when present, a negative urine test result for Bence Jones protein, no evidence of hyperglobulinemia and hypercalcemia, and absence of anemia.,

Histological diagnosis requires immunohistochemical staining of neoplastic plasma cells with strong and diffuse expression of CD138. ${ }^{4}$ Light chain restriction is present in $92 \%$ of the cases and confirms plasmacytoma. However, light chain restriction is not seen in $10 \%$ of extramedullary plasmacytomas, and paucicellular hematopoietic lesions may also result in poor light chain restriction determination. In these two instances, immunohistochemical analysis with CD117 or syndecan 1 may allow the diagnosis of plasmacytoma to be made. To our knowledge, this is the first case of SEPS without light chain restriction to be reported in the medical literature. ${ }^{8}$

It must be acknowledged that patients with SEPS are at risk of developing MM at presentation and therefore have a poor prognosis. ${ }^{9}$ Greipp et al. concluded that the plasma cell labeling index (PCLI) and serum $\beta_{2}$-microglobulin $(\beta 2 \mathrm{M})$ are independent prognostic factors in $\mathrm{MM} .{ }^{10}$ Avilés et al. reported that $\beta 2 \mathrm{M}$ is the most powerful prognostic factor in patients with solitary plasmacytoma. ${ }^{11}$ Therefore, it is advisable to include the determination of $\beta 2 \mathrm{M}$ in the clinical evaluation of patients with solitary plasmacytoma. Determination of PCLI in our patient was not possible, owing to the lack of resources in our institution. Serum $\beta 2 \mathrm{M}$ in our patient was $2.59 \mathrm{mg} / \mathrm{dL}$ (normal range $0.9-2 \mathrm{mg} / \mathrm{dL}$ ). 

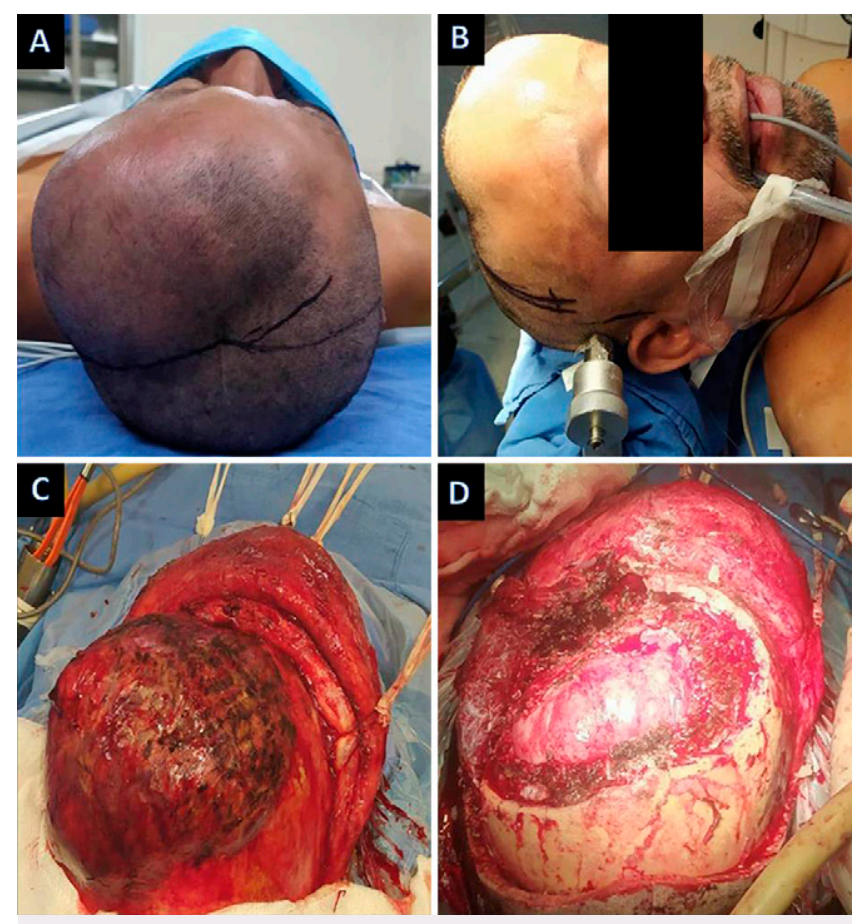

FIG. 2. A and B: The patient was placed supine, and a Mayfield-Keyes triad skull clamp was used for a bifrontal incision and craniectomy. C: Surgical view depicts the tumor, which had already eroded the calvaria and extended subcutaneously. D: Surgical view after tumor removal and drilling of the marginal bone.
Surgical removal followed by postoperative irradiation is the treatment of choice because SEPS is exquisitely radiosensitive. ${ }^{12}$ Nevertheless, some authors advocate reserving radiotherapy for tumor recurrence if total resection has been achieved. ${ }^{4,13}$ Furthermore, there are reports of complete cure after biopsy and radiotherapy., ${ }^{44}$ In our patient, we decided to treat the orbital tumor remnant with radiotherapy, achieving successful results. Thorough hemostasis cannot be overemphasized because plasmacytoma may be a highly vascular tumor and excessive blood loss with cardiac arrest has been reported. ${ }^{4,7}$ Therefore, we believe that preoperative embolization in these cases is crucial, as fatal hypovolemic shock was prevented in our patient. It is advisable to perform craniectomy and cranioplasty in all patients because of the high recurrence rate reported when leaving remnant cells of the tumor in the surrounding bone surface.

\section{Lessons}

SEPS is a diagnosis of exclusion. A thorough biological and radiological survey must be performed at the moment of diagnosis to rule out MM. Bone marrow aspiration and biopsy, serum determination of $M$ protein, complete blood count, serum electrolytes, and urine electrophoresis must be studied in all patients. Furthermore, we encourage the determination of $\beta 2 \mathrm{M}$ as the most important prognostic factor for long-term disease-free survival and prediction of progression to MM. Light chain restriction is absent in some cases because of the excessive osseous tissue and calcification in these tumors, which preclude appropriate histological analysis. In this instance, CD117 and syndecan 1 measurement can be performed.

We strongly suggest preoperative tumor embolization in order to prevent excessive blood loss during surgery. Radical tumor resection must be the primary neurosurgical objective, and radiotherapy could be used when the tumor is small or its resection is not feasible. Cranioplasty is vital to correct skull deformities. Long-term follow-up is required because tumor recurrence or progression to $\mathrm{MM}$ can occur.
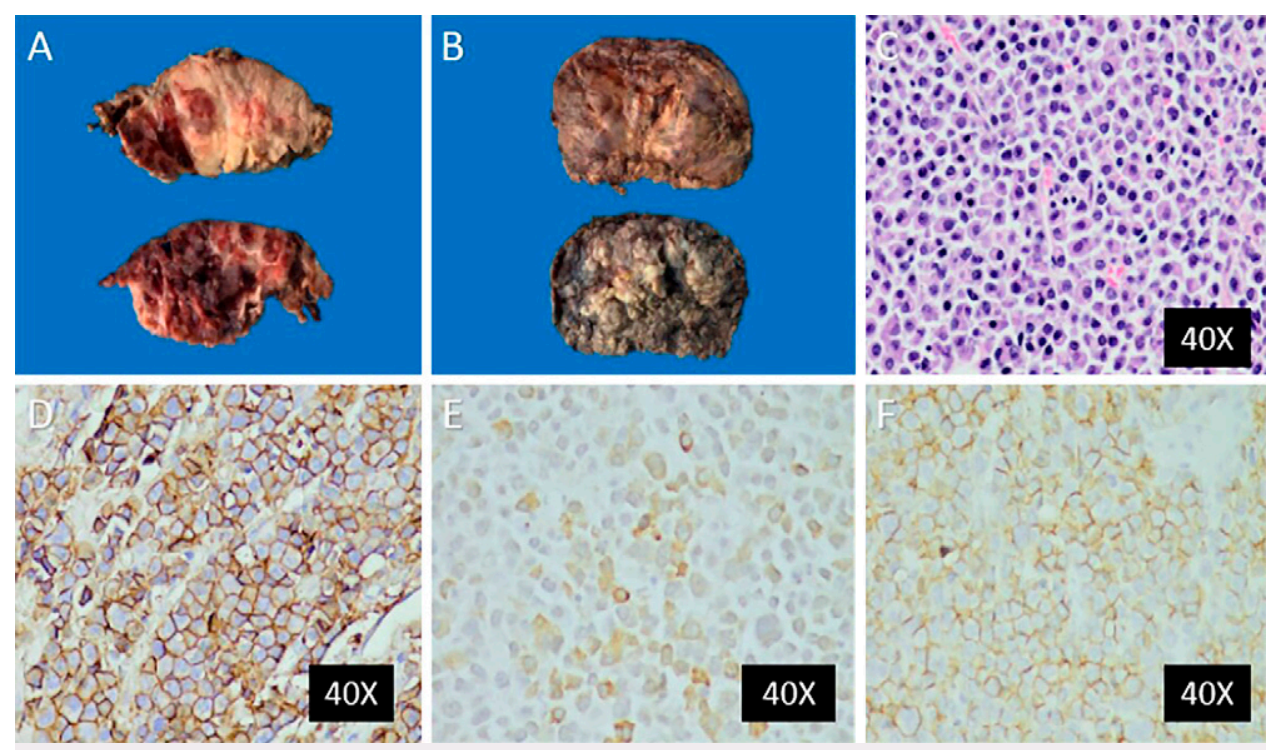

FIG. 3. A and B: Macroscopic view of the tumor reveals an irregular surface and violaceous plaques. C: Microscopic examination demonstrates plasmatic cells. CD138 was diffusely positive (D), as were CD56 (E) and $\operatorname{CD79}(\mathbf{F})$. 

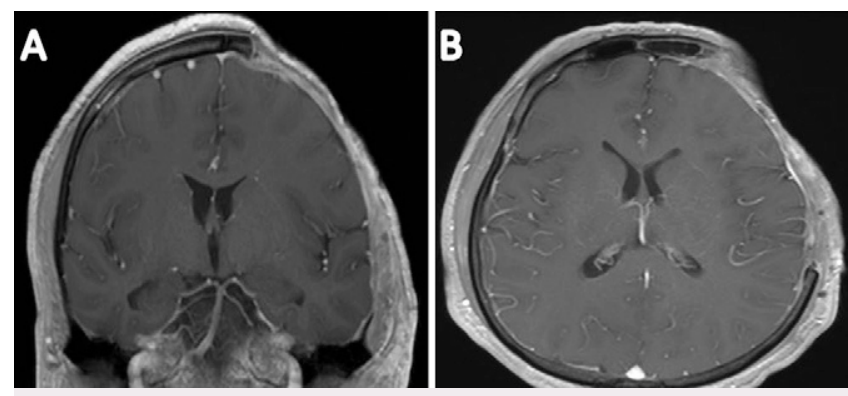

FIG. 4. A and B: Postsurgical MRI shows adequate tumor resection and absence of tumor recurrence.

\section{Acknowledgments}

We are grateful to our institutional pathology department, which obtained precious images for describing this case.

\section{References}

1. Kyle RA. Multiple myeloma and other plasma cell disorders. In: Hoffman R, Benz EJ, Shattil SJ, et al., eds. Hematology: Basic Principles and Practice. 2nd ed. Churchill Livingstone; 1995:1354-1374.

2. Keren DF, Alexanian R, Goeken JA, et al. Guidelines for clinical and laboratory evaluation patients with monoclonal gammopathies. Arch Pathol Lab Med. 1999;123(2):106-107.

3. Tanaka M, Shibui S, Nomura K, Nakanishi Y. Solitary plasmacytoma of the skull: a case report. Jpn J Clin Oncol. 1998;28(10):626-630.

4. Raghavendra $\mathrm{H}$, Kumar MD, Panigraghi M, Reddy SM. Solitary giant extradural plasmacytoma. Asian J Neurosurg. 2017;12(4):721-723.

5. Jacquet $G$, Vuillier J, Viennet $A$, et al. Solitary plasmacytoma simulating pituitary adenoma. Article in French. Neurochirurgie. 1991; 37(1):67-71.

6. Mancardi GL, Mandybur TI. Solitary intracranial plasmacytoma. Cancer. 1983;51(12):2226-2233.

7. Moossy J, Wilson CB. Solitary intracranial plasmacytoma. Arch Neurol. 1967;16(2):212-216.
8. Boo K, Cheng S. A morphological and immunohistochemical study of plasma cell proliferative lesions. Malays J Pathol. 1992;14(1): $45-48$.

9. Boccadoro M, Pileri A. Diagnosis, prognosis, and standard treatment of multiple myeloma. Hematol Oncol Clin North Am. 1997; 11(1):111-131.

10. Greipp PR, Lust JA, O'Fallon WM, et al. Plasma cell labeling index and $\beta_{2}$-microglobulin predict survival independent of thymidine kinase and C-reactive protein in multiple myeloma. Blood. 1993;81(12):3382-3387.

11. Avilés A, Huerta J, Zepeda G, Díaz-Maqueo JC. Serum $\beta_{2}$ microglobulin in solitary plasmocytomata. Blood. 1990;76(8):1663.

12. Bindal AK, Bindal RK, van Loveren $H$, Sawaya R. Management of intracranial plasmacytoma. J Neurosurg. 1995;83(2):218-221.

13. Arienta C, Caroli M, Ceretti L, Villani R. Solitary plasmacytoma of the calvarium: two cases treated by operation alone. Neurosurgery. 1987;21(4):560-563.

14. Strojan P, Soba E, Lamovec J, Munda A. Extramedullary plasmacytoma: clinical and histopathologic study. Int J Radiat Oncol Biol Phys. 2002;53(3):692-701.

\section{Disclosures}

The authors report no conflict of interest concerning the materials or methods used in this study or the findings specified in this paper.

\section{Author Contributions}

Conception and design: Castillejo, Julian, González. Acquisition of data: Castillejo, González, Román. Analysis and interpretation of data: Castillejo, Julian, González. Drafting the article: Castillejo, González. Critically revising the article: Castillejo, Julian, González. Reviewed submitted version of manuscript: Castillejo, Julian, González. Approved the final version of the manuscript on behalf of all authors: Castillejo. Statistical analysis: Castillejo, González. Administrative/ technical/material support: Castillejo, González, Román. Study supervision: Castillejo, Julian, González.

\section{Correspondence}

Luis A. Castillejo: Instituto Mexicano del Seguro Social, Mexico City, Mexico. lancaster081194@gmail.com. 